\title{
Olimpismo e memória: dos baús pessoais de atletas a um acervo público
}

\section{Olympism and memory: from athletes' personal chests to a public collection}

\section{Olimpismo y memoria: del cofre personal de los atletas a una colección pública}

\author{
iD 9 William Douglas de Almeida \\ Universidade de São Paulo, São Paulo, SP, Brasil \\ williamdouglas@usp.br \\ (iD) Rafael Campos Veloso \\ Universidade de São Paulo, São Paulo, SP, Brasil \\ rafaveloso13@hotmail.com \\ (iD) Katia Rubio \\ Universidade de São Paulo, São Paulo, SP, Brasil \\ katrubio@usp.br
}

\begin{abstract}
Resumo: Ao longo de duas décadas trabalhamos na investigação do universo do chamado olimpismo, na história do Movimento Olímpico e, especialmente, no registro das histórias de vida daqueles que são os protagonistas desse fenômeno sociocultural: os atletas. Tal trabalho é realizado com base na metodologia das Narrativas Biográficas. O objetivo deste texto é destacar os processos de construção das narrativas de vida dos atletas com o auxílio de acervo de patrimônio particular. O material de acervo compõe amplo espectro de formas, desde recortes de mídias impressas até a variedade dos objetos biográficos. A preservação de tais acervos, mesmo que realizada de maneira particular, é um elemento fundamental para a memória pública acerca do olimpismo.
\end{abstract}

Palavras-chave: Jogos Olímpicos, acervo, esportes, narrativas biográficas. 


\begin{abstract}
Over the past two decades, we worked in the investigation of the universe of the so-called Olympism, in the history of the Olympic Movement and, especially, in the recording of the life stories of those who are protagonists of this socio-cultural phenomenon: the athletes. This job is based in the methodology of the Biographical Narratives. The purpose of this article is to highlight the processes of construction of life narratives with the aid of a private heritage collection. The collection material comprises an extensive spectrum of shapes, from cutouts of printed media to a variety of biographical objects. The preservation of such collections, even if carried out in a particular way, is a fundamental element for public memory around Olympism.
\end{abstract}

Keywords: Olympic Games, collection, sports, biographical narratives

Resumen: Durante dos décadas, trabajamos en investigar el universo del llamado Olimpismo, en la historia del Movimiento Olímpico y, especialmente, en registrar las historias de vida de los protagonistas de este fenómeno sociocultural: Ios atletas. Este trabajo es hecho con base en la metodología de Narrativas Biográficas. El propósito de este texto es destacar los procesos de construcción de narrativas de vida con la ayuda de un acervo de patrimonio privado. El material de colección comprende un amplio conjunto de formas, desde recortes de medios impresos, hasta la variedad de objetos biográficos. La preservación de los acervos, aunque sea de manera particular, es un elemento fundamental para la memoria pública en torno al Olimpismo.

Palabras-Clave: Juegos Olímpicos, colección, deportes, narraciones biográficas

Submetido em: 15-07-2020

Aceito em: 15-09-2020 
Olimpismo e memória: dos baús pessoais de atletas a um acervo público William Douglas de Almeida • Rafael Campos Veloso • Katia Rubio

\section{Introdução}

Há cem anos, em 1920, o Brasil participou pela primeira vez de uma edição dos Jogos Olímpicos. Desde então, mais de 2.100 atletas representaram o país naquele que é considerado o maior evento esportivo do planeta. Apesar de a Carta Olímpica prever que as participações são individuais, nenhum atleta pode participar dos Jogos sem estar vinculado a um comitê olímpico nacional. Além disso, ao participar de uma edição olímpica, o atleta utiliza-se de vários elementos que o vinculam a um país: as cores do uniforme, a bandeira e o hino que soa em caso de vitória.

Para melhor compreender o olimpismo brasileiro, realizamos um trabalho de busca pelos personagens que compuseram a história do país nos Jogos: os atletas. Em duas décadas, foram realizadas aproximadamente 1,4 mil entrevistas, a maioria delas presencial, com registro em vídeo. Desse material surgiram vários trabalhos, como livros, artigos acadêmicos, dissertações e teses. Durante a construção deste projeto, desenvolveu-se o método das Narrativas Biográficas, cujo objetivo principal era capturar elementos da trajetória de vida dos atletas, bem como as construções subjetivas dessa vivência e da formação de sua identidade. O referencial teórico inicial da pesquisa foi baseado em autores que se dedicaram aos estudos da memória, tais como Halbwachs (1990), Ricoeur (1988), Benjamin (2012), Le Goff (2013), Bosi (1994) e Meihy (1994).

A interação promovida entre os pesquisadores e os atletas teve início nos primeiros contatos para reconhecimento da proposta e o agendamento do encontro para a realização da entrevista, que sempre começava com um convite: "Por favor, conte-me a sua história de vida". Surpresos, muitos dos entrevistados respondiam a essa questão com outra indagação: "A minha história de vida, ou de vida esportiva?". A partir daí, o atleta tinha a liberdade de situar a narrativa de sua trajetória pessoal. Esse início foi um marco e serviu como dado para os estudos sobre a identidade atlética e 
Olimpismo e memória: dos baús pessoais de atletas a um acervo público William Douglas de Almeida • Rafael Campos Veloso • Katia Rubio

pessoal de atletas brasileiros, bem como forneceu elementos para a compreensão sobre a transformação do papel social do atleta em diferentes momentos históricos.

Ao optar por um modelo de interação, diferentemente de uma entrevista semiestruturada, fugiu-se daquilo que Medina (2000) definiu como uma camisa de força. Em entrevistas dirigidas ou questionários, a postura autoritária determinada pela condução da interação com o sujeito busca confirmar uma teoria ou hipótese. Quando se trabalha com a interação, o que se tem é a interpretação dos fatos baseada na ampliação de vozes. Segundo Medina (2000), um bom investigador é aquele que adota uma postura dialógica e democrática, humanizando o contato com o entrevistado, realizando o que ela chama de diálogo possível.

A realização de um diálogo possível se dá quando há a apropriação do contexto da entrevista por parte do pesquisador, ou seja, ele se mune de informações acerca da pessoa e de suas realizações, do momento histórico em que ela viveu, as ocorrências públicas, para que possam emergir conteúdos subjetivos, muitas vezes não elaborados quando da realização do feito narrado. Nessa direção, Gomes (2008) ressalta a importância do domínio do contexto pelo pesquisador para que uma relação dialógica seja estabelecida. A importância de tal domínio também é destacada por Giglio (2013), que constata a existência de várias conexões entre as histórias de vida dos sujeitos com o momento histórico em que esses fatos se deram.

O mesmo cuidado foi observado por parte dos atletas. Muitas foram as ocasiões em que caixas cheias de objetos biográficos, como medalhas, roupas, álbuns fotográficos, além de pastas contendo jornais e revistas antigas, repousavam sobre a mobília do lugar onde o encontro ocorria. Utilizado como mapa para transitar em espaços da memória, esse material ajudava os sujeitos na narrativa de suas trajetórias. Em muitos casos, alguns dos entrevistados chegaram a oferecer esse material raro como doação para o acervo da pesquisa. Até mesmo objetos de grande valor pessoal foram oferecidos, caso houvesse o interesse na construção de um 
Olimpismo e memória: dos baús pessoais de atletas a um acervo público William Douglas de Almeida • Rafael Campos Veloso • Katia Rubio

"memorial" olímpico. Este é um expediente comum quando se trabalha com memória, conforme aponta Kotre (1997):

\begin{abstract}
Em geral 'pistas para a recordação' apontam o caminho. Folheie um velho anuário de ginásio e você verá as tais 'pistas' em funcionamento. Os nomes e rostos trarão de volta uma torrente de recordações. O mesmo farão as anotações de despedida que seus colegas de classe podem ter escrito no livro. Volte à escola propriamente dita, caminhe pelos corredores e salas de aula, e você descobrirá ainda mais pistas. Lugares autobiográficos que retêm lembranças ilustram o fato de que a memória é dependente do contexto. (KOTRE, 1997, p. 49-50).
\end{abstract}

Infelizmente, apesar de participar dos Jogos Olímpicos há um século, a única estrutura existente no Brasil é o "Museu Cidade Olímpica e Paralímpica", localizado no Rio de Janeiro, próximo ao estádio João Havelange, que foi utilizado durante os Jogos de 2016. Apesar de reconhecermos o esforço e méritos da ação, compreendemos que, isolada, ela ainda é insuficiente para preservar toda a memória do olimpismo brasileiro, havendo um grande potencial inexplorado. Além desse museu, é preciso destacar outras iniciativas que ocorrem de maneira fragmentada, como centros de memória específicos de alguns clubes. Também há acervos privados de colecionadores que guardam material inédito e precioso, sem acesso do público.

Apesar de serem espaços importantes, ao longo de duas décadas podemos constatar que grande parte da história olímpica brasileira se encontra fragmentada em arquivos particulares, sob a guarda de atletas ou de familiares daqueles que já faleceram. São pessoas que buscam da melhor maneira possível preservar a história pessoal, que é também coletiva, do esporte nacional.

Assim sendo, este ensaio tem como objetivo apresentar algumas das histórias que foram resgatadas com o uso de objetos pessoais e materiais de acervos particulares para problematizar a 
Olimpismo e memória: dos baús pessoais de atletas a um acervo público William Douglas de Almeida • Rafael Campos Veloso • Katia Rubio

necessidade de discussão sobre a conservação da memória olímpica nacional.

\section{O caso dos objetos biográficos do ciclista Ricardo Magnani}

O ciclista José Ricardo Magnani foi integrante do primeiro grupo de ciclistas brasileiros a participar dos Jogos Olímpicos, fato ocorrido na edição de Berlim, em 1936. Buscamos como fonte oral para este trabalho o relato de sua filha única, Cléa Magnani, que, de posse de objetos biográficos (fotografias, medalhas, uniformes etc), puxava das profundezas dos anos os elementos e o vigor para reconstruir a memória do pai. Encontramos nos signos dos objetos biográficos de José Ricardo Magnani, dispostos por sua filha no momento da entrevista, elementos significativos que auxiliaram a entrevistada a organizar o fluxo narrativo, no exercício de reviver a memória do pai por meio da linguagem falada. Antes do encontro com Clea, algumas (poucas) fontes nos informaram que Magnani era paulistano, do bairro da Barra Funda, nascido em 6 de março de 1913. Teria sido um dos fundadores da União Ciclística Bandeirante e foi presidente da Federação Paulista de Ciclismo e Motociclismo, afastando-se dessa função para defender a equipe do Juventus, do tradicional bairro da Mooca, até 1944. Constava, ainda, seu falecimento em 24 de Julho de 1966 - neste ano, Clea completara apenas 15 anos de idade.

Na sala da casa de Clea - local do encontro para a entrevista - foram dispostos muitos objetos em uma mesa de centro e que não pertenciam ao décor da moradia. Esses objetos se tratavam de um grande quadro de madeira escura de medalhas antigas com cores desgastadas, alternando entre o marrom, o dourado opaco e a prata, flâmulas e emblemas bordados, e dois uniformes de lã com cores muito vivas, um verde e amarelo e o outro, um 
Olimpismo e memória: dos baús pessoais de atletas a um acervo público William Douglas de Almeida • Rafael Campos Veloso • Katia Rubio

casaco de lã mais grossa na cor azul marinho, que exibia na fronte o Cruzeiro do Sul bordado.

Clea deu início ao relato dos feitos do pai enquanto puxava uma grande caixa de papelão que estava encostada no braço do sofá ao seu lado. O conteúdo da caixa era um velho álbum confeccionado pelo próprio pai. O álbum não mentia a idade: possuía páginas que tinham a cor amarela no centro, que se transformavam em marrom quando alcançavam as bordas e exalava um cheiro que irritava as narinas. Clea tomou assento até o fundo do sofá para se recostar com a coluna ereta, juntando os joelhos para formar o melhor apoio possível para o álbum que é grande e desajeitado. Abriu na primeira página, e na primeira fotografia recordou sobre o dia, sobre o pai e sobre o feito. E seguiu: segunda fotografia; segunda página - eles seriam a bússola que guiaria Clea no fluxo temporal e narrativo de reconstituição da memória do pai.

José Ricardo Magnani tivera o cuidado de organizar todos os registros possíveis de sua vida como atleta do ciclismo de estrada. O álbum contém desde o registro da primeira vitória, ainda no final da década de 1920, até as últimas aventuras do atleta nas estradas, em meados da década de 1940. Os recortes de jornal, fotografias pessoais, cartas, homenagens e até relatórios escritos de próprio punho foram minuciosamente organizados pelo ciclista em ordem cronológica. Nas margens das fotografias, ele indicava a lápis claro a data e o local daquela cena. O velho quadro de medalhas deitado sobre a mesa central não escapou ao preciosismo do registro cronológico. Dentro de sua moldura de madeira grossa e escura, o quadro, que por si só tinha o formato de um brasão medieval, segurava medalhas perfiladas que narravam a ordem em que as conquistas se deram e os feitos foram realizados. Terminadas as páginas do álbum, passamos a explorar os objetos sobre a mesa. A entrevistada pousava um a um na palma de sua mão, como se esperasse no afago do objeto a revelação de sua história. Depois, nos passava com o cuidado de quem protege algo muito frágil, narrando ao mesmo tempo as aventuras do pai para aquela conquista. Chegada a vez de dar voz às medalhas do 
Olimpismo e memória: dos baús pessoais de atletas a um acervo público William Douglas de Almeida • Rafael Campos Veloso • Katia Rubio

quadro, percebeu que algumas estavam fora de suas posições originais. Decretou uma rápida pausa na narrativa para recolocar as medalhas em suas posições originais. Com a ajuda das lembranças das conquistas do pai, devolveu uma a uma, narrando cada evento.

Passados alguns meses, nos dias que antecederam a realização dos Jogos Olímpicos do Rio de Janeiro, Clea se juntou a diversos atletas olímpicos brasileiros no estádio Paulo Machado de Carvalho - Pacaembu - para uma homenagem aos olímpicos brasileiros durante a passagem da tocha olímpica por São Paulo. Clea andou por aquele túnel, onde já caminharam muitos heróis do futebol, e subiu ao gramado na condição de representar a presença do pai. 0 dia da realização dessa homenagem ocorreu casualmente no $50^{\circ}$ aniversário de falecimento de José Ricardo Magnani. Para reforçar sua presença simbólica, ela levou alguns objetos, como a medalha de participação do pai nos Jogos Olímpicos de Berlim, em 1936, e teve a ideia de vestir as netas que a acompanhavam com os uniformes da delegação brasileira de ciclismo que Magnani utilizou, no intuito de materializar no enraizamento dos objetos, durante a homenagem, a presença do pai. Ao receber em nome do pai a medalha dourada com relevos que diziam "Honra em ser atleta olímpico", alongou o braço na direção do céu, no intuito de entregá-la por lá, e com os olhos mirados para o azul sem fim homenageou: "É a roda da vida e da morte na qual nos encontraremos ainda, ${ }^{1}(. .$. Uma honraria oitenta anos após sua participação, antes tarde do que nunca. Esta é pra você, meu pail".

\section{A família Gorauskas e o basquete nacional}

Em busca da história de Radvilas Gorauskas, atleta olímpico de basquete que representou o Brasil nos Jogos Olímpicos de 1972, já

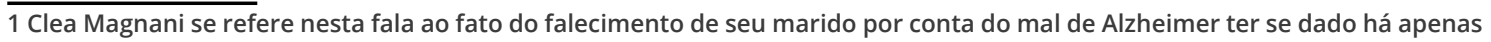
quatro dias, e a data da homenagem ter conciliado casualmente no dia do $50^{\circ}$ aniversário de falecimento do pai. 
Olimpismo e memória: dos baús pessoais de atletas a um acervo público William Douglas de Almeida • Rafael Campos Veloso • Katia Rubio

falecido, fomos até o município de Piracicaba, no interior paulista, onde morava o irmão dele, Mindaugas, também ex-jogador de basquete e contemporâneo nas quadras. Eles nasceram na Lituânia, durante a década de 1940. À época, aquele país havia sido ocupado por soviéticos, por causa da Segunda Guerra Mundial. Quando Radvilas tinha 6 anos e Mindaugas 5, eles foram levados para um acampamento canadense, onde precisaram aguardar pela possibilidade de migrar. Ali tiveram a oportunidade de escolher entre alguns países e a família optou pelo Brasil, onde já havia um tio, Bóris Chernorviki, que estava radicado em São Paulo.

A carreira de ambos começou no clube Espéria, à época chamado Floresta. Em 1962, após se destacarem, os irmãos foram convidados a jogar pelo Sírio. A complicada transição foi parar na Justiça Desportiva, pois ambos foram acusados de profissionalismo, algo proibido naquele período, já que o basquete era amador. Superado o problema com os clubes, os irmãos tiveram de enfrentar outro entrave burocrático: a naturalização. Resolvidos os problemas, enfim, Mindaugas e Radvilas puderam se dedicar ao basquete, e voltaram a ter destaque. No ano de 1968, Radvilas foi chamado para defender a seleção brasileira nos Jogos Olímpicos da Cidade do México, mas pediu dispensa, pois estava com o casamento marcado. Quatro anos depois, em 1972, Radvilas já era considerado um veterano, mas tinha a confiança do técnico Kanela, que o convocou para a disputa dos Jogos Olímpicos de Munique. Dessa vez, não houve impeditivo e ele pôde participar da competição.

A entrevista na qual baseamos as informações acima foi concedida por Mindaugas Gorauskas no ano de 2017. À época, Mindaugas recuperava-se de um procedimento cirúrgico e havia passado por uma traqueostomia. Impossibilitado de falar, ele contou com a ajuda dos filhos Dênis e Douglas e de um vasto material de acervo para contar a história da família. Além de apontar os dedos para o material relevante no acervo, ele também escreveu bilhetes, acrescentando informações e detalhes sobre a trajetória dele e do irmão. Apesar das limitações físicas enfrentadas por 
Olimpismo e memória: dos baús pessoais de atletas a um acervo público William Douglas de Almeida • Rafael Campos Veloso • Katia Rubio

Mindaugas devido à traqueostomia, foi possível resgatar com os bilhetes e o acesso ao material do acervo pessoal grande parte da história da família Gorauskas e do basquete nacional. Organizado em pastas, com muitos recortes de jornal e fotografias, o acervo pessoal foi fundamental para o resgate de algumas histórias que eram desconhecidas até mesmo de Dênis e Douglas.

Halbwachs (1990, p. 54) aponta que "cada homem está mergulhado ao mesmo tempo ou sucessivamente em vários grupos. Cada grupo, aliás, se divide e se restringe, no tempo e no espaço". No caso de Mindaugas e Radvilas, além dos vínculos familiares, eles compartilharam, simultaneamente, a presença em outros grupos, como nos clubes nos quais atuaram. Após mais de três décadas da morte de Radvilas, porém, falamos de memórias ressignificadas por tudo aquilo que Mindaugas viveu. E, claro, por sentimentos como a saudade. Mindaugas morreu meses após conceder a entrevista ao projeto, em maio de 2017.

\section{Szabó, a referência no polo aquático nacional}

Nascido em 15 de março de 1933, na Hungria, Aladar Szabó se destacou desde jovem nas piscinas. No ano de 1953, ele participou da conquista do Campeonato Mundial de Polo Aquático pela seleção húngara. Na temporada seguinte, esteve na conquista do Mundial Universitário e também do Campeonato Europeu. Aliado ao esporte, Szabó seguia os estudos e concluiu dois cursos superiores na Hungria: Educação Física, em 1955, e Ciências Econômicas, em 1956.

Ainda no ano de 1956, ele integrava a seleção que se preparava para a disputa dos Jogos Olímpicos de Melbourne, mas decidiu desertar. Fixou-se na Itália, mas dois anos depois migrou para o Brasil, a convite de João Havelange, então presidente da Confederação Brasileira de Desportos. 
Olimpismo e memória: dos baús pessoais de atletas a um acervo público William Douglas de Almeida • Rafael Campos Veloso • Katia Rubio

Apesar dos esforços da confederação e do desejo do atleta, ele não conseguiu se naturalizar a tempo de disputar os Jogos Olímpicos de Roma, em 1960. O processo só foi concluído em 1962 e, a partir de então, Szabó passou a ser convocado para a seleção brasileira. Ele foi um dos principais jogadores na campanha do título dos Jogos Pan-Americanos de São Paulo, em 1963. No ano seguinte, fez parte da seleção brasileira que disputou os Jogos Olímpicos de Tóquio. Foi professor universitário e depois empresário, dono de uma academia de natação. Morreu em São Paulo, em outubro de 1982.

As informações acima foram coletadas em uma entrevista realizada com a filha de Szabó, Isabella, realizada no Rio de Janeiro, onde ela vive. Isabella nasceu após o pai se aposentar das piscinas, mas guarda um grande acervo de fotos, documentos e recortes de jornais que o citam. Um dos documentos guardados é um currículo de Szabó, escrito a mão por ele, no qual pudemos encontrar vários detalhes sobre a carreira esportiva. O material de Isabella foi também fonte para uma das principais pesquisas já realizada sobre o polo aquático nacional (TELLES, 2002).

\section{A ressignificação de sujeitos e memórias}

Um dos desafios de se trabalhar com a narrativa de terceiros e com fontes documentais é lidar com a imprecisão de alguns dados. Todavia, essa é uma adversidade que o pesquisador também enfrenta diante das falas dos indivíduos que foram os protagonistas da história. Veloso e Rubio (2016) enfatizam que pesquisas realizadas com este método valorizam as singularidades:

Mesmo que o sujeito tenha relatado ao narrador no momento presente do acontecimento suas impressões e análises sobre o fato, estes terão duração apenas no instante do fenômeno, pois a reconstrução da memória operara no instante do presente. 
Olimpismo e memória: dos baús pessoais de atletas a um acervo público William Douglas de Almeida • Rafael Campos Veloso • Katia Rubio

Entretanto, este terceiro que possui a missão de narrar, nos dá uma impressão do que foi a vida do personagem. (VELOSO; RUBIO, 2016, p. 240).

Alguns objetos e documentos servem como uma importante ferramenta na construção de narrativas. Outros, ganham um novo significado com o passar dos anos e passam a ser vistos pelos familiares como uma preservação dos sujeitos. Veloso e Rubio (2016, p. 240) afirmam ainda que os objetos biográficos podem "exercer a função do farol que vai iluminar o que o breu dos anos deixou fugidio", condição relevante para a reconstituição das memórias, condicionadas naturalmente em seu caminho de submersão e apagamento ao longo do tempo. Para os autores, recobrando as postulações de Ecléa Bosi acerca dos objetos biográficos na função de reavivamento do substrato memorativo, tais objetos possuem ligações de enraizamento e identidade com o possuidor e, enfim, envelhecem juntos, apresentando em seus corpos a degradação do tempo.

No caso da narrativa biográfica de José Ricardo Magnani, feita por sua filha, Clea Magnani, obtivemos a leitura da realidade de um pai-atleta nos relatos incendiados de afeto que nos transmitiam as imagens de como era seu lar e seus gestos nos dias de grandes feitos esportivos. A narradora seguiu o velho álbum de fotografias e recortes de jornais antigos, confeccionado por seu pai, como guia cronológico e, ainda mais importante, como organizador do substrato memorativo no fluxo narrativo, com o intuito de recordar e contar suas façanhas no esporte. Isabella Szabó, da mesma forma, nos proporcionou uma leitura comentada dos recortes de jornais e fotografias conservados por ela.

Além das situações descritas acima, a importância da preservação de acervos particulares é evidenciada em um exemplo descrito por Rosina (2018). Foi por meio de um documento guardado pelo velejador Burkhard Cordes que foi possível confirmar que o velejador Ralph Conrad também esteve entre os convocados pelo Brasil para participar dos Jogos Olímpicos de 1968. Além de docu- 
Olimpismo e memória: dos baús pessoais de atletas a um acervo público William Douglas de Almeida • Rafael Campos Veloso • Katia Rubio

mentos históricos, vale destacar que na sala da casa de Burkhard Cordes estão objetos olímpicos de inestimável valor: a medalha de bronze conquistada por ele nos Jogos Olímpicos de 1968, e outras duas, uma de ouro e outra de prata, conquistadas pelo pai dele, Otto Cordes, que atuou pela equipe de polo aquático da Alemanha nas edições olímpicas de 1928 e 1932.

Assim como as narrativas podem apresentar momentos de dúvidas e incertezas, é preciso ter cuidado ao analisarmos o conteúdo de arquivo. Giglio (2013) aponta que jornais podem conter erros e imprecisões, assim como documentos oficiais. Lemos (2008) também considera tais elementos importantes, e diz que tanto os jornais quanto documentos podem ser úteis ao pesquisador, mas devem ser sempre estudados em relação a outras fontes, o que ajuda na sua compreensão e a evitar a imprecisão de dados. O currículo manuscrito de Aladar Szabó, por exemplo, cita que ele teria sido medalhista de ouro com a seleção húngara de polo aquático nos Jogos Olímpicos de Helsinque, em 1952, mas não conseguimos confirmar este dado em outras fontes. Isso, todavia, não invalida o restante do acervo preservado por Isabella.

\section{Considerações Finais}

A existência de um arquivo olímpico oficial não isentaria a possibilidade dessas imprecisões, mas elas poderiam ser menores ou até mesmo apresentadas como diferentes versões para um fato, caso houvesse uma instituição ou um grupo responsável pela curadoria deste material. Todavia, o modo como hoje boa parte desses documentos e objetos se encontram, distribuídos em acervos particulares, acaba sendo um complicador não apenas para os pesquisadores interessados no olimpismo, mas, também, ao público em geral.

Durante a pesquisa, foi possível observar que há um entrelaçamento entre trajetórias pessoais e uma construção coletiva - a 
Olimpismo e memória: dos baús pessoais de atletas a um acervo público William Douglas de Almeida • Rafael Campos Veloso • Katia Rubio

participação brasileira nos Jogos Olímpicos -, evidenciando as dimensões particulares, nacionalistas e universalistas relacionadas ao evento, conforme apontado por MacAloon (2010). Não defendemos um "confisco" dos objetos e documentos utilizados pelos atletas durante as edições olímpicas, mas a existência da possibilidade de que alguns destes objetos sejam oferecidos - voluntariamente - para que componham parte de uma narrativa, pois "a sensação de satisfação causada por uma revisão da vida pode ser ampliada ao se ver a própria vida como parte de uma peça teatral maior" (KOTRE, 1997, p. 177). Dessa forma, o acervo particular, em sua potência biográfica, exerce o papel de farol e organizador do fluxo narrativo daquele que se propõe ao exercício de reconstruir uma trajetória de vida de outrem ou mesmo própria. Uma preservação cuidadosa de acervos considerados particulares ajudaria a manter também viva parte da história brasileira nos Jogos Olímpicos.

Essa peça teatral universal, que conhecemos como Jogos Olímpicos, não existiria sem seus atores - os atletas. A ausência de mais organizações que preservem a memória dos Jogos relega às sombras muitos destes sujeitos, que se dedicaram durante anos para atingir o nível de excelência que os colocou na história do esporte nacional. Hoje, a maior parte desta história continua esparsa, e, apesar de apresentar um caráter nacional e universal, sobrevive apenas em arquivos pessoais.

\title{
Referências
}

\author{
BENJAMIM, Walter. Magia e técnica, arte e política: ensaios \\ sobre literatura e história da cultura. São Paulo: Brasiliense, 2012. \\ BOSI, E. Memória e sociedade: Lembranças de velhos. São \\ Paulo: Companhia das Letras, 1994. \\ GIGLIO, Sérgio Settani. COI x FIFA: a história política do futebol \\ nos Jogos Olímpicos. 2013. Tese (Doutorado em Ciências) - Escola
}


Olimpismo e memória: dos baús pessoais de atletas a um acervo público William Douglas de Almeida • Rafael Campos Veloso • Katia Rubio

de Educação Física e Esporte, Universidade de São Paulo, São Paulo, 2013.

GOMES, M. B. Entrevista Biográfica. Trabalho apresentado com o nome de Biografia e Subjetividade. In: CONGRESSO INTERNACIONAL SOBRE PESQUISA (AUTO) BIOGRÁFICA, 3., 2008, Natal. Anais [...]. Natal: Edfurn, 2008. p. 1-12.

HALBWACHS, Maurice. A memória coletiva. São Paulo: Vértice. Editora Revista dos Tribunais, v. 189, 1990.

KOTRE, John. Luvas brancas: como criamos a nós mesmos através da memória. Tradução de Flávia Villas-Boas. São Paulo: Mandarim, 1997.

LE GOFF, J. História \& Memória. Campinas: Editora da Unicamp, 2013.

LEMOS, Danilo Luis Rodrigues. A história social do movimento olímpico brasileiro no início do século XX. 2008. Tese (Doutorado em Ciências) - Escola de Educação Física e Esporte, Universidade de São Paulo, São Paulo, 2008.

MACALOON, J. J. Olympic games and the theory of spectacle in modern societies. In: GIRGINOV, V. The Olympics: a critical reader. Routledge, 2010. p. 80-107.

MEDINA, C. Entrevista, o diálogo possível. São Paulo: Ática; 2000.

MEIHY J.C.S.B. Definindo história oral e memória. Cadernos CERU, São Paulo, v. 2, n. 5, 1994, p. 52-60.

RICOEUR, P. L'Identité Naarative. Revue Sprit, Paris, n. JUIL./ AOÛT, p. 295-304, 1988.

ROSINA, Dhênis. Entre narrativas, fragmentos e estilhas: construções de atletas brasileiros sobre os jogos olímpicos do México de 1968. 2018. Tese (Doutorado em Ciências) - Escola de Educação Física e Esporte, Universidade de São Paulo, São Paulo, 2018. 
Olimpismo e memória: dos baús pessoais de atletas a um acervo público William Douglas de Almeida • Rafael Campos Veloso • Katia Rubio

VELOSO, R.C.; RUBIO, K. Objetos biográficos: tempos vivos para as narrativas. In: RUBIO, Katia (org.). Narrativas biográficas: da busca à construção de um método. São Paulo: Laços, 2016. p. 229 - 242.

TELLES, S. C. C. A identidade do jogador de polo aquático e o mito da masculinidade. 2002. Dissertação (Mestrado em Educação Física) - Faculdade de Educação Física, Universidade Gama Filho, Rio de Janeiro, 2002.

\section{Financiamento}

Esta pesquisa contou com apoio financeiro do Conselho Nacional de Desenvolvimento Científico e Tecnológico (CNPq) e da Fundação de Amparo à Pesquisa do Estado de S. Paulo (Fapesp).

\section{Publisher}

Universidade Federal de Goiás. Faculdade de Educação Física e Dança. Publicação no Portal de Periódicos UFG. As ideias expressadas neste artigo são de responsabilidade de seus autores, não representando, necessariamente, a opinião dos editores ou da universidade. 